\title{
Tobacco Use, Combined Prevention/Cessation Research
}

National Cancer Institute

\section{Source}

National Cancer Institute. Tobacco Use, Combined Prevention/Cessation Research. NCI

Thesaurus. Code C15992.

Studies to test and implement interventions among groups of individuals that are designed to both prevent the initiation of tobacco use and stop current tobacco use.

$(\mathrm{NCl} / \mathrm{TRIP})$ 